
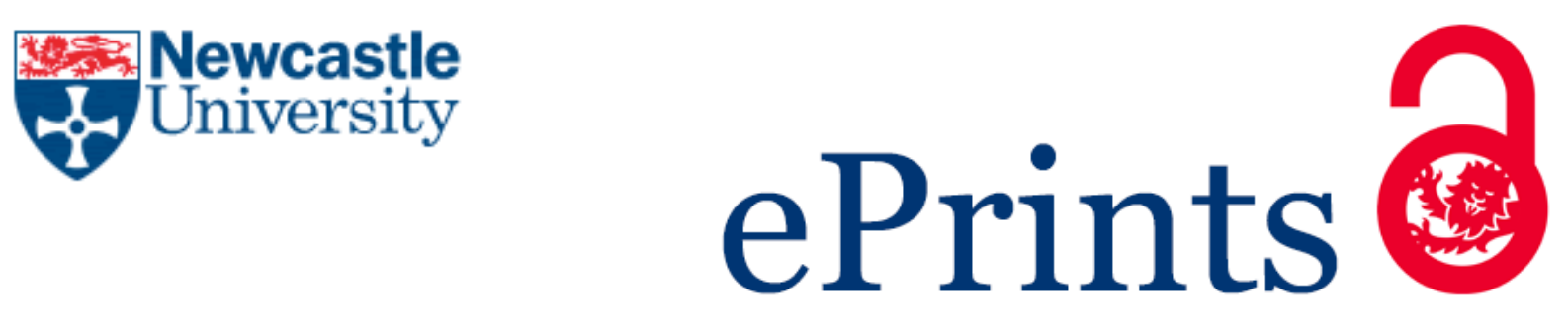

Huang Y, Wang Y, Chen H, Zhang X, Mondol JD, Shah N, Hewitt N.

Performance analysis of biofuel fired trigeneration systems with energy storage for remote households. Applied Energy 2016, (ePub ahead of Print).

Copyright:

(C) 2016. This manuscript version is made available under the CC-BY-NC-ND 4.0 license

DOI link to article:

http://dx.doi.org/10.1016/j.apenergy.2016.03.028

Date deposited:

$19 / 04 / 2016$

Embargo release date:

23 March 2017

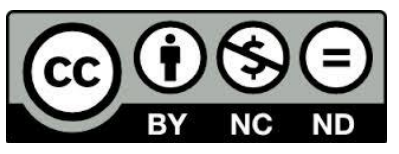

This work is licensed under a

Creative Commons Attribution-NonCommercial-NoDerivatives 4.0 International licence 


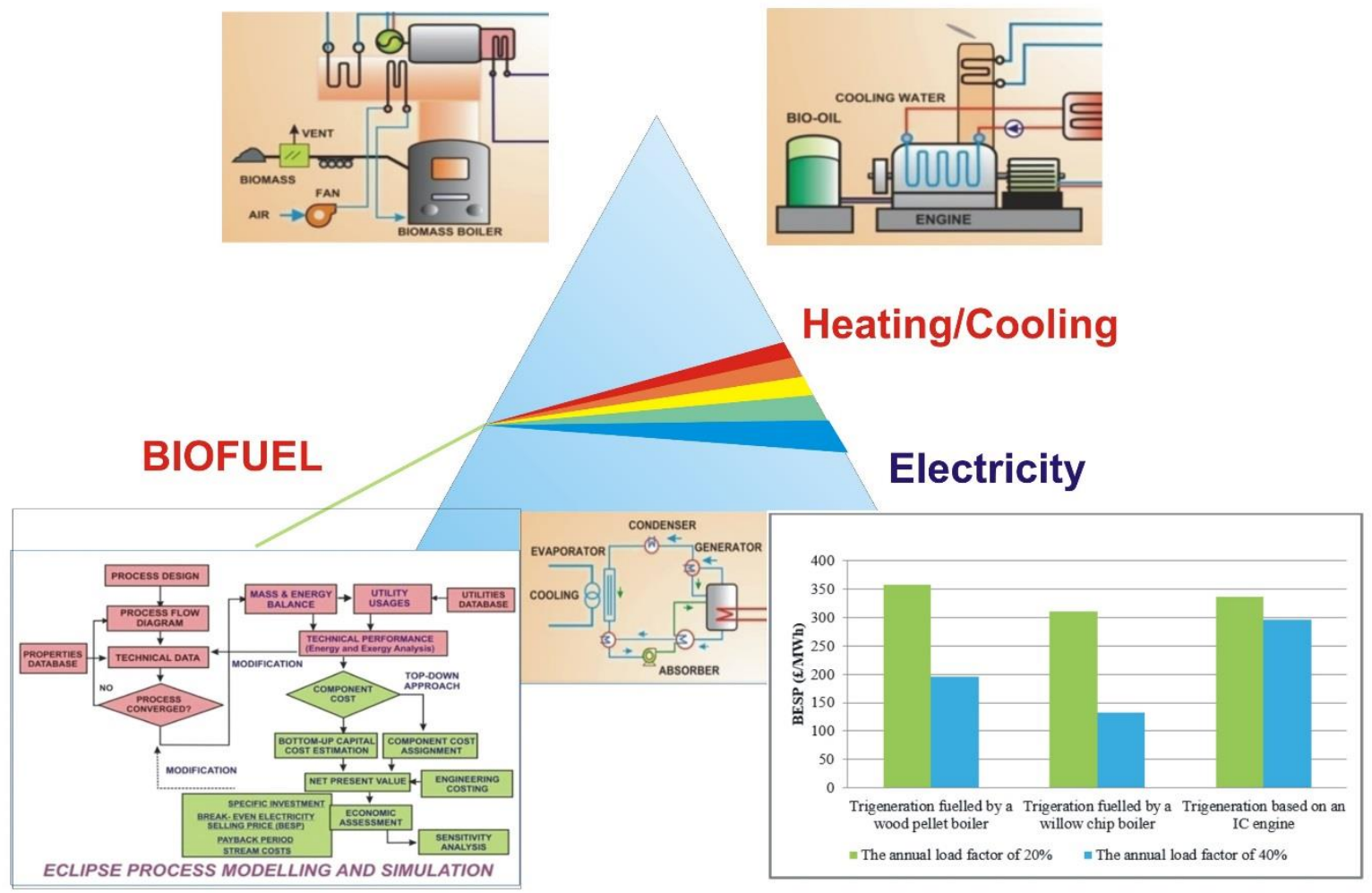




\title{
Performance Analysis of Biofuel Fired Trigeneration Systems with Energy Storage for Remote Households
}

\author{
Y. Huang ${ }^{[a]^{*}}$, Y.D. Wang ${ }^{[b]}$, Haisheng Chen ${ }^{[c]}$, Xinjing Zhang ${ }^{[c]}$ \\ J. Mondol ${ }^{[a]}$, N. Shah ${ }^{[a]}$ and N.J. Hewitt ${ }^{[a]}$
}

\author{
${ }^{[a]}$ Centre for Sustainable Technologies, School of the Built Environment, Ulster University, Jordanstown, \\ BT37 0QB, UK \\ ${ }^{[b]}$ Sir Joseph Swan Centre for Energy Research, Newcastle University, Newcastle Upon Tyne, NE1 7RU, \\ UK \\ ${ }^{[c]}$ Institute of Engineering Thermophysics, Chinese Academy of Sciences, 100190, Beijing, China
}

\begin{abstract}
Technical and economic modelling and performance analysis of biofuel fired trigeneration systems equipped with energy storage for remote households were carried out. To adapt the dynamic energy demand for electricity, heating and cooling, both electrical and thermal energy storage devices were integrated to balance larger load changes. The proposed systems were modelled and simulated by using the ECLIPSE process simulation package. Based on the results achieved, technical performance and emissions from the system had been examined. The impact of electrical and thermal energy storages was also investigated. Finally, an economic evaluation of the systems was performed. It was found that for a household, the internal combustion (IC) engine based trigeneration/combined heat and power (CHP) system is more suitable for heat to electricity ratio value below 1.5 and the biomass boiler and Stirling engine based system is beneficial for heat to electricity energy demand ratio lying between 3 and 3.4. Techno-economic analysis of the modelled trigeneration systems showed efficiencies of around $64 \%$ to $70 \%$ and Break-even Electricity Selling Prices of around $£ 313 / \mathrm{MWh}$ to $£ 357 / \mathrm{MWh}$ when fired by biofuels. Results also indicated that the economic viability of this type of trigeneration systems is significantly improved by the Renewable Heat Incentive (RHI) and Feed-In Tariffs schemes (FITs) by up to $46 \%$.
\end{abstract}

Key words: biomass, techno-economic modelling, trigeneration, energy storage, energy demand profile

*Corresponding author email address: y.huang@ulster.ac.uk 
NOMENCLATURE

$\mathrm{AR}$ - as received

BESP - Break-even electricity selling price

CAPEX - capital expenditure

CHP - Combined heat and power

DAF - Dry and ash free

FITs - Feed in Tariffs scheme

IC engine - Internal combustion engine

LHV - Lower heating value

MSW - Municipal solid wastes

NPV - Net present value

RHI - Renewable heat incentive

SI - Specific investment 


\section{INTRODUCTION}

Electricity generation is a major use of fossil fuels and the demand for electricity is growing steadily throughout the developed world and dramatically in the developing areas. However the huge amount of consumption of fossil fuels causes enormous carbon dioxide emissions and leads to the global warming. In order to deal with environmental issues mainly from the burning of fossil fuels, the replacement of all or part of these carbon intensive fuels with renewable energy sources, such as biomass, solar energy and wind power is an obvious alternative for the future to meet targets to reduce greenhouse gas emissions levels. In certain areas of the world solar thermal/power is a promising option. However seasonal variations and weather conditions have a very strong impact on the solar thermal/power output [1,2]. Wind energy may provide a better solution but its intermittent nature and a lack of heat output means that wind alone would not be appropriate [3, 4]. To secure and diversify the supply of energy biomass and/or biofuels, such as combustible agricultural residues, energy crops, wood and woody wastes from forestry and industry, bio wastes (municipal solid wastes - MSW) from cities/towns and vegetable oil can provide the best energy solution if managed properly [5-7] There are benefits to using biomass in generating electric and thermal energy to rural areas, where end users are located close to the farm. This would reduce the number of miles travelled significantly, resulting in lower transportation costs. The main environmental benefit is from substituting for fossil fuel combustion and consequent carbon emissions [8]. As a source of low carbon energy, bioenergy conversion processes will produce nearly zero net $\mathrm{CO}_{2}$ emissions with less impact on the environment than fossil fuels because the resulting $\mathrm{CO}_{2}$ was previously captured by the plants being combusted during the whole life cycle $[9,10]$. Building new transmission lines and supplying electric power to isolated rural areas where it is often difficult to access, unlike those in urban areas, could prove to be expensive and challenging [11]. In order to give these homes to access affordable electricity services and promote sustainable economic development, an off-grid power generation could be the most promising and economic option. Basic domestic energy use in the UK includes electricity, hot water and space heating. According to the statistics, in 2013 the energy consumption in the domestic sector makes up more than $29 \%$ of all energy used in the UK [12]. The conventional method is to purchase electricity from the national grid for supplying household electrical appliances and a part of the main heating system during most of the winter season. In fact, the average efficiency of coal power plants is around $38 \%$ in the UK [13]. This means that around $62 \%$ of waste heat generated in the 
power generation process is rejected to atmosphere. Making the maximum use of fuel energy with minimum losses, small scale co-generation systems for household applications could reach overall conversion efficiencies to over $70 \%$ and even higher $[14,15]$, which is significantly more efficient than generating each of these separately.

In this paper a small scale biomass/or biodiesel fuelled trigeneration system that can simultaneously provide electricity, hot water and space heating/or cooling for dwelling houses in an isolated area is proposed. This system is mainly based on the integration of a combined heat and power (CHP) unit which generates electricity and heat, and a thermally driven chiller which produces a cooling effect, leading to higher process efficiencies in comparison with stand-alone generation in large power plants [16]. Although home air cooling is currently less common in the UK compared to southern European and Asian countries, such as Greece, Italy and China there will still be a potential for off-grid trigeneration applications in the future. One reason for this is the UK's changeable weather and a general increase in summer temperatures recent years as a result of human influence on climate [17]. This means that the UK's domestic cooling market is hoped to be a steady growth in the future. The overall objective of this study is to investigate the key technical, environmental and economic issues in a domestic application and to establish the commercial viability of the process. For this study, the energy consumption profile of the selected house is used as the case study. To adapt dynamic range of electricity and heat demands and provide system flexibility, both electrical and thermal energy storage devices are incorporated into the system. The proposed trigeneration process is modelled and simulated using the ECLIPSE process simulation package [18]. The Eclipse models established have been validated by the laboratory and pilot scale work and are being used to predict the behaviour of appropriately sized commercial scale system, enabling informed decisions regarding techno-economic feasibility.

\section{MATERIALS AND METHODS}

\subsection{Biomass feedstock properties}

The properties of the feedstock are important to the selection of suitable conversion processes. In order to investigate the impact of the feedstock properties, such as energy content, moisture level and chemical composition on the energy efficiency, operation and emissions of the trigeneration systems two common types of biomass fuels (wood pellets and willow chips) are chosen for this 
assessment study. Certain quantitative values have been assumed as "typical" for a biomass combustion plant experiencing a European climate [19]. To evaluate the internal combustion (IC) engine based trigeneration system, a type of biodiesels is also selected. Biodiesel is an environmentally friendly alternative liquid fuel that can be used in any diesel engine without modification [6]. The selected biodiesel is derived from the Jatropha oil through a transesterification process. The main properties, calorific values, proximate and ultimate analysis of the biodiesel and biomass used are shown in Table 1.

\subsection{Electricity and heat demand profiles in the selected houses}

In order to identify house's energy consumption patterns it is necessary to have house's energy consumption profiles. As mentioned, the applications of trigeneration would be beneficial to houses when there is a good requirement of heating and cooling loads to match the demands for electricity. Moreover when the thermal demands during the cold weather are almost balanced by increasing energy required for cooling in the hot summer months, the trigeneration system can be operated at a relatively high occupancy value. Figure 1 shows an example of the electricity demand for a typical dwelling house [20]. Based on measured load data it can be seen that the average daily electricity consumption is around $11 \mathrm{kWh}$ and the maximum power of the house reaches to $6.8 \mathrm{~kW}$. Figure 1 also indicates that electric loads can be divided into two peak times, i.e. 3 hours in the morning (6am-9am) and 4 hours in the evening (5pm-9pm). During the peak periods the consumption of electricity accounts for over $87 \%$ of the total electricity consumption. Figure 2 illustrates a test building constructed for measuring heat demand profiles and exploring the best way to make a house more efficient. This two semi-detached two storey building was built on the Jordanstown Campus, Ulster University, Northern Ireland. Two similar families were living in neighbouring homes. Figure 3 shows seasonal variations of the heat demand in this test building for the period from $1 / 12 / 2014$ to $30 / 11 / 2015$. The results indicate that the total daily thermal consumption was about $71 \mathrm{kWh}$ with maximum of $146 \mathrm{kWh}$. Higher heat demand is mainly due to lower outdoor temperatures in the winter and in some cases higher occupancy. During the summer months the average heat consumption was around $30 \mathrm{kWh}, 58 \%$ less than the winter months, mainly providing domestic hot water, resulting in a daily heat demand of $15 \mathrm{kWh}$ per house. As illustrated in Figure 4, the heat demand pattern also presents two peaks during a day, one heat 
power peak in the morning and another peak in the afternoon, accounting for over $70 \%$ of the total heat consumption.

\subsection{Electric and Thermal Energy Storage}

To adapt to varying electric and thermal demands over a 24 hour period and maintain adequate process efficiency, both electricity and heat produced must be stored for later use when the system is shut off. Based on the power demand profile of the household, the battery storage capacity was set to $13 \mathrm{kWh}$ with a peak power output of $10 \mathrm{~kW}$. This capacity included discharging limit and conversion loses. During periods of electricity generation a large amount of waste heat is produced from the process. To manage and store the waste heat recovered, a large well insulated buffer tank was installed which supplies space heating and hot water through heat exchangers when needed. This storage tank helps meet house heating demand during the day time in order to shift electricity peak during the day/evening. Generally the sizing of the thermal energy storage for domestic applications depends on the household's heat consumption, influenced by the size of the house and other issues such as energy-efficient architecture and thermal insulation. To meet on daily space heating and hot water demands, the thermal storage tank was sized to hold 600 litres of hot water. In order to estimate the heat capacity of the thermal storage tank the flow temperature of hot water and the temperature of the returning water are assumed to be $70^{\circ} \mathrm{C}$ and $45^{\circ} \mathrm{C}$ respectively. Based on an assumed temperature difference between hot water inlet and outlet streams the total heat output would be around $17 \mathrm{kWh}$, almost half of the average heat consumption, and satisfy off peak heat requirement.

\subsection{Economic factors and indices}

Economic evaluation of the selected cases was carried out using net present value (NPV) concepts. As the main indicator, the breakeven electricity selling price (BESP) of the trigeneration systems was calculated using the financial modelling of ECLIPSE. Conventional natural gas CHP systems usually have life spans between 18 and 20 years, therefore biomass trigeneration systems were assumed to have similar lifetimes. Project life of the trigeneration system was set to 20 years. The discounted cash flow rate was set to $8 \%$. The market price of biomass is quite variable and also depends on the property of biomass supplied. For our modelling, we used an average price of 8.5 $£ / G J$ (at $30 \%$ moisture content) for clean willow chips and 13£/GJ for dried wood pellets [21]. To 
estimate heating and hot water cost a traditional oil fired central heating system was used. The oil price was assumed to be $620 £ /$ tonne, which is equivalent to $0.5 £ /$ litre. The proposed trigeneration systems, which generate electricity, heat and cooling for internal use, will not incur any taxes for energy production.

\subsection{Modelling options}

The trigeneration system powered by biofuels for a rural household application at this scale is still the novel process. To allow suitable analyses associated with the trigeneration systems, three options were created. The systems described were assumed to be technically viable for long-term placement in commercial applications. For each option, the likely capital expenditures, operating and maintenance costs along with the BESP for the trigeneration process under certain conditions were determined. To summarise, these options are as follows:

Option 1: wood pellet fuelled trigeneration system based on a Stirling engine along with hybrid energy storages;

Option 2: willow chip fuelled trigeneration system based on a Stirling engine along with hybrid energy storages;

Option 3: biodiesel fuelled trigeneration system based on an internal combustion (IC) engine along with hybrid energy storages.

\subsection{Modelling Software Tool}

To ensure that evaluations and comparisons were carried out in a consistent and reliable manner, modelling and simulation were performed using the ECLIPSE process simulation package. ECLIPSE was developed for the European Commission by the Research Centre of the University of Ulster and has been successfully used to analyse a wide range of energy conversion systems, such as coal fired power plants and biomass energy systems [22, 23]. ECLIPSE, as shown in Figure 4 , is a personal-computer-based package containing all of the program modules necessary to complete rapid and reliable step-by-step technical, environmental and economic evaluations of chemical and allied processes including mass, energy and exergy balance, capital costing, and economic analyses. ECLIPSE requires the user to have technical knowledge of the processes involved. 
At the initial stage, process flow diagrams composed of modules and streams are generated within ECLIPSE. After specifying the stream inputs and technical features of individual modules, the mass and energy balance is determined via enthalpy calculations for each stream. This is achieved by converging the information specified in the compound database, as well as in the input streams and modules. The information gained during this second stage of simulation forms the base for identifying critical components within the plants that may be subjected to extreme physical and chemical exposure conditions. In the third stage, the package computes the amount of energy consumed by individual utilities and compounds and provides the power plant net output. Finally, fuel and other stream costs are added and the economic viability of the examined systems is evaluated (including the BESP at zero net present value - here referred to the levelised cost of electricity (LCOE)).

\section{PROCESS CONFIGURATION AND DESCRIPTION}

\subsection{Biomass fuelled trigeneration system based on a Stirling engine}

The proposed trigeneration system fuelled by biomass contains the following components: a conventional biomass boiler and heat transfer section; a Stirling engine unit for power generation, which is the basic primary mover of the system; waste heat recovery heat exchangers for heating process; an absorption chiller for cooling process and electric and thermal energy storage, as outlined in Figure 6. As a promising technology the Stirling engine has a good efficiency, low emissions, low noise levels and the high performance at partial load [24, 25]. The Stirling engine with air as the working fluid is considered in this study. Normal biomass storage facilities are provided from where the biomass is pre-treated and then transferred to the trigeneration process in sufficient quantities for 10-15 days throughout. Biomass fuel is then burned in a traditional gratefired boiler, designed with well-established reliable technologies. Approximately $20 \%$ excess air is used in the combustion chamber to ensure complete combustion. Hot gases are passed through a heat exchanger which transfers heat into the Stirling engine working fluid. The Stirling engine gains and releases heat and recycles the same air to change the pressure of sealed air and generates electricity as a result. Waste heat from the exhaust gas and cooling source is recovered and delivered to the thermal tank for space heating/or hot water purposes. In the warm months of summer the amount of heat is used in an absorption chiller to produce chilled water for air conditioning or refrigeration. 
3.2 Biodiesel powered trigeneration system based on an IC engine

The proposed IC engine based trigeneration system contains a diesel engine, which is the basic primary mover of the system, a generator, heat recovery and storage system; and an absorption cooling system, as seen in Figure 7. A constant speed diesel engine genset with a rated output of $5.2 \mathrm{~kW}$ is used for modelling and assessment at different operating conditions. This is the minimum capacity which may be commercial available [20]. As a cogeneration application, thermal power at both low temperature and high temperature can be recovered from the engine cooling water and the exhaust gas [26]. The system is operated in the following way:

- The IC engine genset is run with the selected biodiesel;

- Waste heat is recovered from the engine cooling system and exhaust gas, and stored in the thermal tank;

- A Li-Br absorption chiller powered by a part of the waste heat is used to generate chilled water for air cooling in a house when necessary.

\section{RESULTS AND DISCUSSION}

\subsection{Technical data overview}

The proposed systems were successfully evaluated using the ECLIPSE process simulator, with technical and environmental performance results in Table 2.

In Option 1, the fuel used is wood pallets. Electricity generated from the Stirling engine is 3.2kWe; the total available waste heat recovered from the system is $10.9 \mathrm{~kW}$. In the warm months of summer the cooling effect generated is $4.4 \mathrm{~kW}$ (at EER of 0.6). The overall efficiency in the trigeneration mode is around 67\% (LHV) while the mean electricity efficiency is $19.4 \%$. In Option 2, the fuel used is willow chips. Since calculations have been made for the same configurations, electrical and thermal outputs of Option 2 would not be changed too much when the feedstock is switched from wood pellets to willow chips. The LHV trigeneration efficiency is found to be $65.4 \%$, less than $1.6 \%$ of Option 1 . This efficiency can be improved if willow chips can be dried without diverting energy from the system. Using willow chip fuel, however, would be the cost benefit as it is a cheaper fuel than wood pellets in the market. Options 1 and 2 are found to achieve the heat to power output ratio of proximately 3.4. This means that a biomass combustion based trigeneration system offers relatively higher heat to power output ratio and is appropriate in the 
average UK household for space heating and sometimes hot water. In Option 3, the feedstock used is biodiesel. Compared to Option 1, the electricity output rises to $5.2 \mathrm{kWe}$ as the engine is operated at a fixed load $(5.2 \mathrm{~kW}$ output power) but total heat recovered from the engine cooling system and exhaust gases falls to $7.6 \mathrm{~kW}$, leading to around $30 \%$ reduction compared with Options 1 and 2. Giving $2.2 \mathrm{~kW}$ of the cooling effect, the overall trigeneration efficiency is $60.1 \%$ (LHV), while the mean electricity efficiency rises to $30 \%$, resulting in a heat to power out ratio of around 1.5 . The result of Option 3 indicates that the IC engine based trigeneration system usually has a high electrical efficiency, resulting in lower heat to power output ratio than biomass combustion based system. A supplementary heat source, therefore, may be needed to meet high heating demand during winter months due to insufficient heat for domestic applications in the UK.

With regard to the environmental performance, $\mathrm{CO}_{2}$ emissions from the stack are estimated in the simulation to be $512 \mathrm{~g} / \mathrm{kWh}, 522 \mathrm{~g} / \mathrm{kWh}$ and $504 \mathrm{~g} / \mathrm{kWh}$ from Options 1, 2 and 3, respectively. As compared with Option 3, the use of biomass as feedstocks may increase $\mathrm{CO}_{2}$ emissions, but not significantly. This is because the output power of Option 3 is much higher than that of Options 1 and 2. Regarding $\mathrm{CO}_{2}$ emissions to the atmosphere, when biomass/or biofuel fuelled systems are operated for 1270 hours a year, ranging from 6 to 9 tonnes of carbon dioxide can be saved through the trigeneration technology. Financial benefits from $\mathrm{CO}_{2}$ reductions due to these trigeneration applications will depend on the level of Carbon Credits available.

\subsection{Economic simulation results}

An economic analysis, as shown in Table 3, was done to determine the BESP of electricity generated. Since economic results are too detailed to be discussed here, certain parameters have been selected to assess the technology used.

For Option 1, the minimum capital investment is $£ 21500$, resulting in a specific cost of $6656 £ / \mathrm{kWe}$ [24]. The relatively high specific cost is mainly due to the small size of the process. At a wood pellet cost of $220 £ /$ tonne on an as received basis the total annual feedstock cost is $£ 1280$. When the capital expenditure (CAPEX) return of $£ 2110$ and an annual heat/or cold saving of $£ 1720$ are taken into account, a BESP of $357 £ / M W h$ is estimated, which is much more expensive than electricity from the grid. For Option 2, the minimum capital investment is given at $£ 23500$, 
resulting in a specific cost of $7150 £ / \mathrm{kWe}$, slightly higher than that of Option 1 . Considering willow chip costs of $100 £ /$ tonne, the BESP of the trigeneration installation is given at $313 £ / \mathrm{MWh}$, which is $44 £ / M W h$ lower than that of Option 1 due to its low feedstock cost. For Option 3, the minimum capital investment is given at $£ 11000$, leading to a specific cost of $2128 £ / \mathrm{kWe}$, almost two times lower than the Stirling engine-based trigeneration systems. With biodiesel cost of $1136 £ /$ tonne the total annual feedstock cost is $£ 2830$. Taking a CAPEX return of $£ 1080$ and an annual heat/cold saving of $£ 1180$ into account, a BESP of $336 £ / M W h$ is calculated, which is higher than that of Option 2, increasing more than 7\% although Option 3 has a much lower specific cost than Option 2. This means that higher feedstock costs have a significant impact on the price of electricity generated for small scale trigeneration systems.

As reported, the economic viability of small scale CHP depends on financial support coming from capital grants, low interest loans or renewable energy generation tariffs for the solid fuel systems [27]. Financial incentives are also essential for economic viability of a residential biomass heating application [28]. For biomass and biodiesel fuelled trigeneration residential systems the Renewable Heat Incentive (RHI) and Feed-In Tariffs (FITs) schemes play a considerable role to help meet the 2020 renewable target, ensuring that heat and electricity generated from renewable energy sources is commercially attractive compared to fossil fuel alternatives. As can be seen in Table 3, when RHI and FITs provide a continuous income stream up to 10 years, a reduction in the BESP could be up to $40 \%$ for Option 1, 46\% for Option 2 and $8 \%$ for Option 3. Option 3 is less sensitive to RHI and FITs due to the cost of feedstock and its low heat to electricity ratio impacting on the BESP.

\subsection{Sensitivity Analysis}

The sensitivity study covers the impacts of a wide range of uncertainties on the techno-economic viability of the project during the plant life cycle. In this study, taking into account the application of micro trigeneration systems for residential buildings, the focus will be given to two parameters, namely (a) system load factors, and (b) feedstock costs.

Basically the trigeneration system studied is assumed to operate for around 1750 hours a year. However it is possible that this will not always be the case, and so it is helpful to find out how the 
BESP would vary with the load factor, as illustrated in Figure 8. In comparison with the base line of a load factor of $20 \%$, it can be seen that the BESP for Options $1 \& 2$ would decrease $48 \%$ and $57 \%$, respectively, when increasing the load factor to $40 \%$, although the total process capital cost is increased slightly due to an increase in the capacity of energy storage. However increasing load factor would not significantly reduce the BESP for Option 3. This is because the BESP improvement in Option 3 is offset by high oil prices while the load factor increases and fuel consumption rises. Therefore to drive down electricity costs it is necessary for a trigeneration system to be run at a high load factor when the feedstock used has a relatively low price. The typical implementation may be carried out by supplying electricity, heat or cold to two or three adjacent houses at the same time.

The biofuel feedstock cost is also an important factor for determining the electricity generation price. This influence is expressed in the sensitivity analysis performed from $-30 \%$ to $+30 \%$ of normal biofuel prices (see Table 3). As illustrated in Figure 9, the sensitivity of the BESP to the percentage change in feedstock costs for Options 1, 2 and 3 is $2.43,1.67$ and $3.37 £ / \mathrm{MWh}$ per percent change in feedstock prices, respectively. As already noticed, when the feedstock cost is relatively high (e.g. Option 3) this becomes more volatile. This economic characteristic, however, has the potential to become more attractive if the biodiesel production cost could be decreased from its current level.

\section{CONCLUSION}

A number of options have been modelled and simulated to assess the technical and economic viability of trigeneration systems fuelled by biofuels for remote households. The followings are the main conclusions from this study.

It is technically feasible to use wood pellets, willow chips and biodiesel as the feedstock to operate the trigeneration systems driven by either a Stirling engine or IC engine;

Stirling engine based trigeneration would be beneficial to the households if the heat to electricity energy demand ratio is in the range of 3 and 3.4;

IC engine based trigeneration would be more suitable for the households with a lower heat to electricity ratio (less than 1.5 ); 
The moisture content of biomass feedstock has an impact on the overall efficiency of the trigeneration system but the impact is not significant;

The potential of $\mathrm{CO}_{2}$ savings per household is likely to be in the range of 6.1 and 8.9 tonnes per year compared to a fossil fuel fired trigeneration system;

Either increasing load factors or reducing feedstock costs would improve the BESP significantly; The BESP of Stirling engine based trigeneration is dominated by process capital costs;

The BESP of IC engine based trigeneration is dominated by the fuel cost;

The additional income, such as Renewable Heat Incentive (RHI) and Feed in Tariffs scheme (FITs) has a considerable influence on the BESP. 


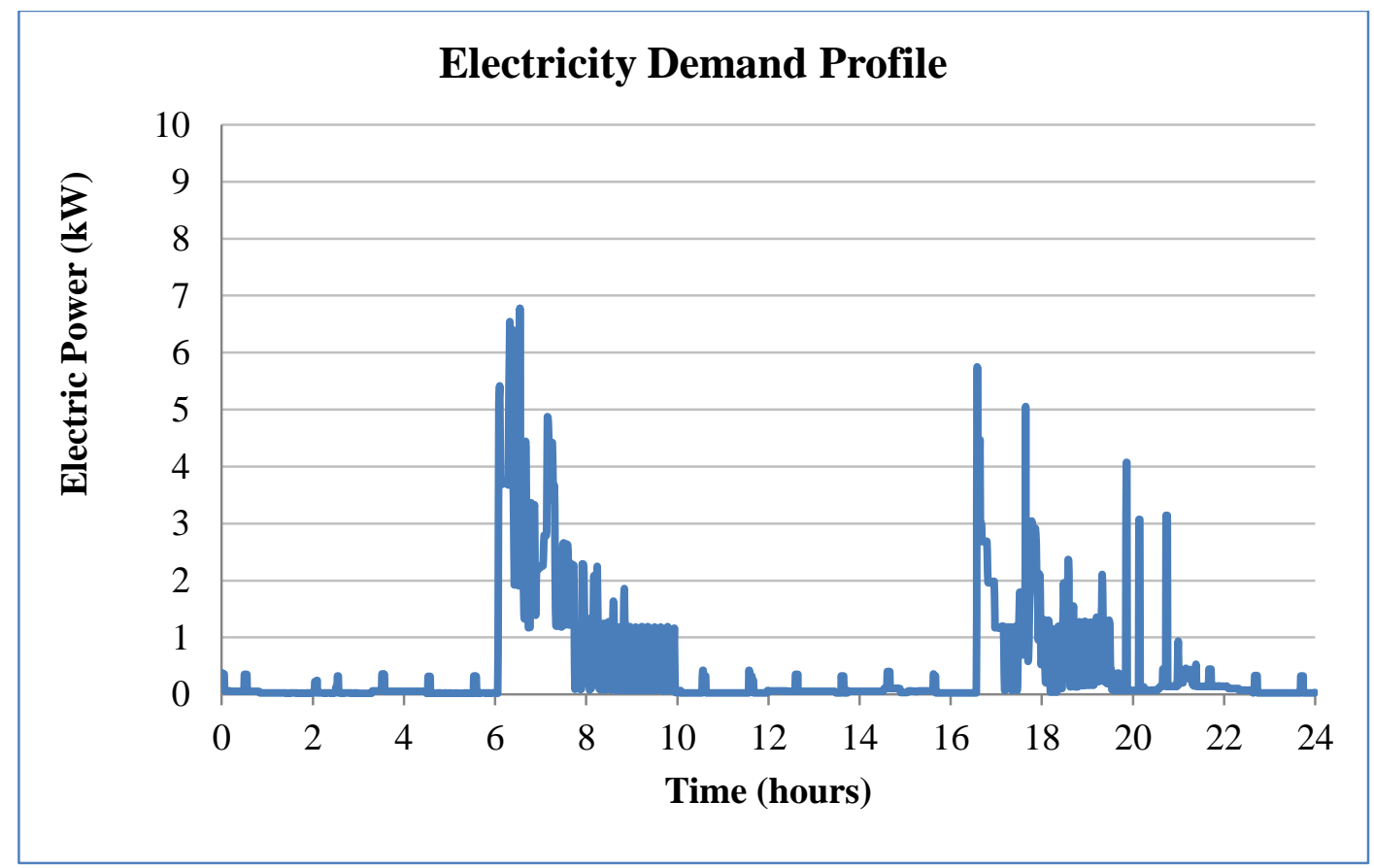

Figure 1 Hourly electricity demand profile of the selected household

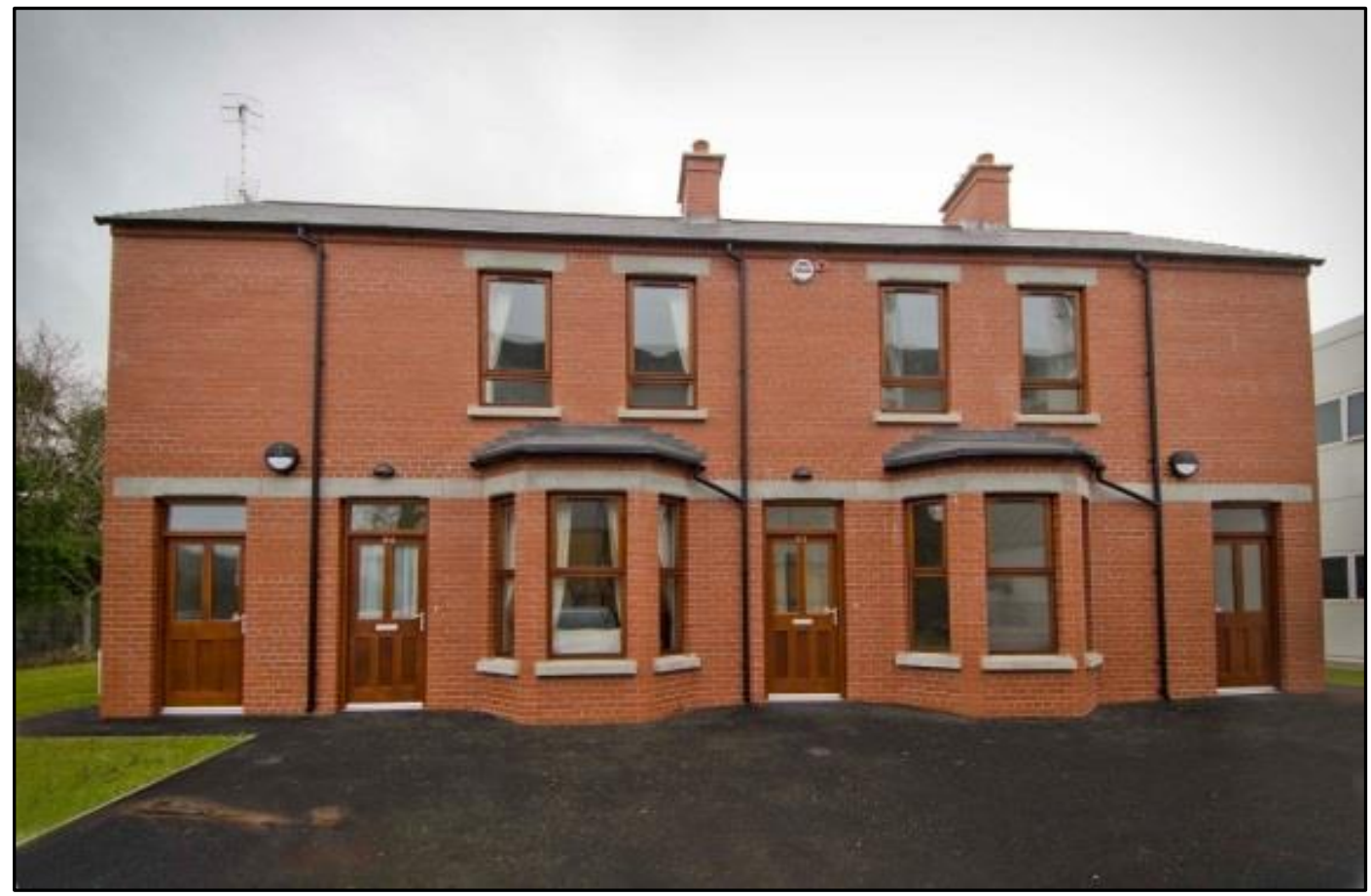

Figure $\mathbf{2}$ Test dwelling houses at Ulster University 


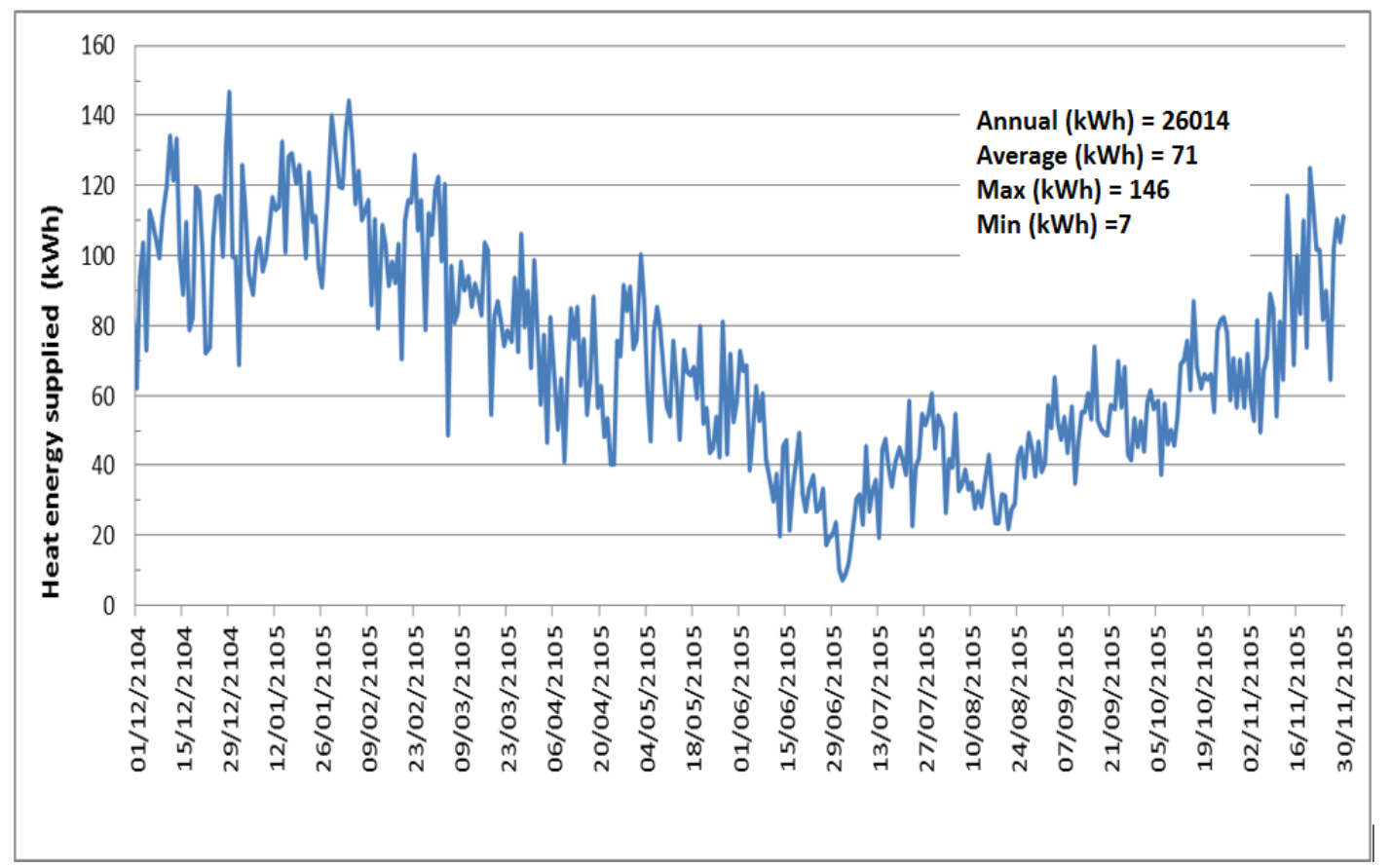

Figure 3 Daily heat demand profile of the selected houses

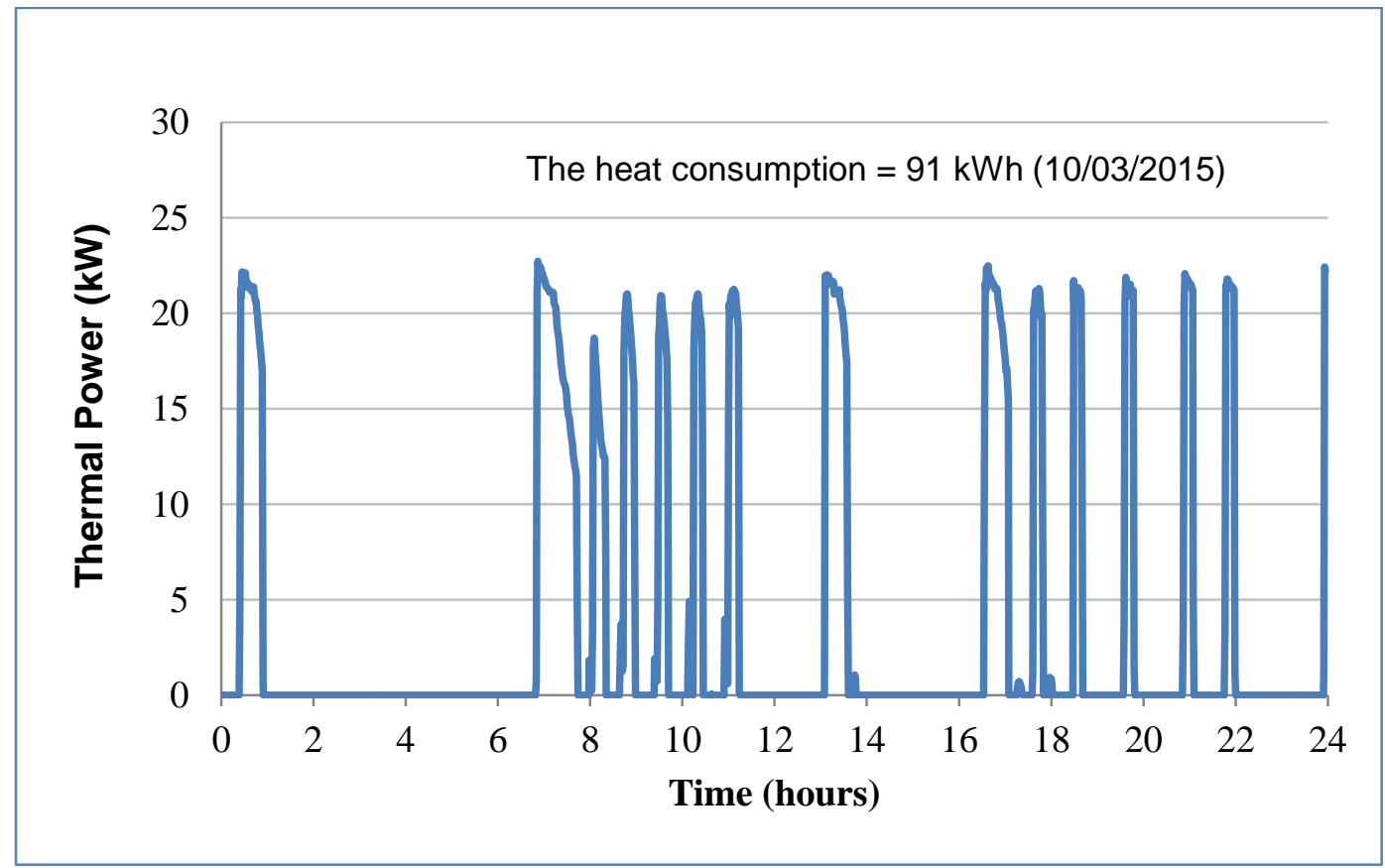

Figure 4 Hourly heat demand profile of the selected houses 


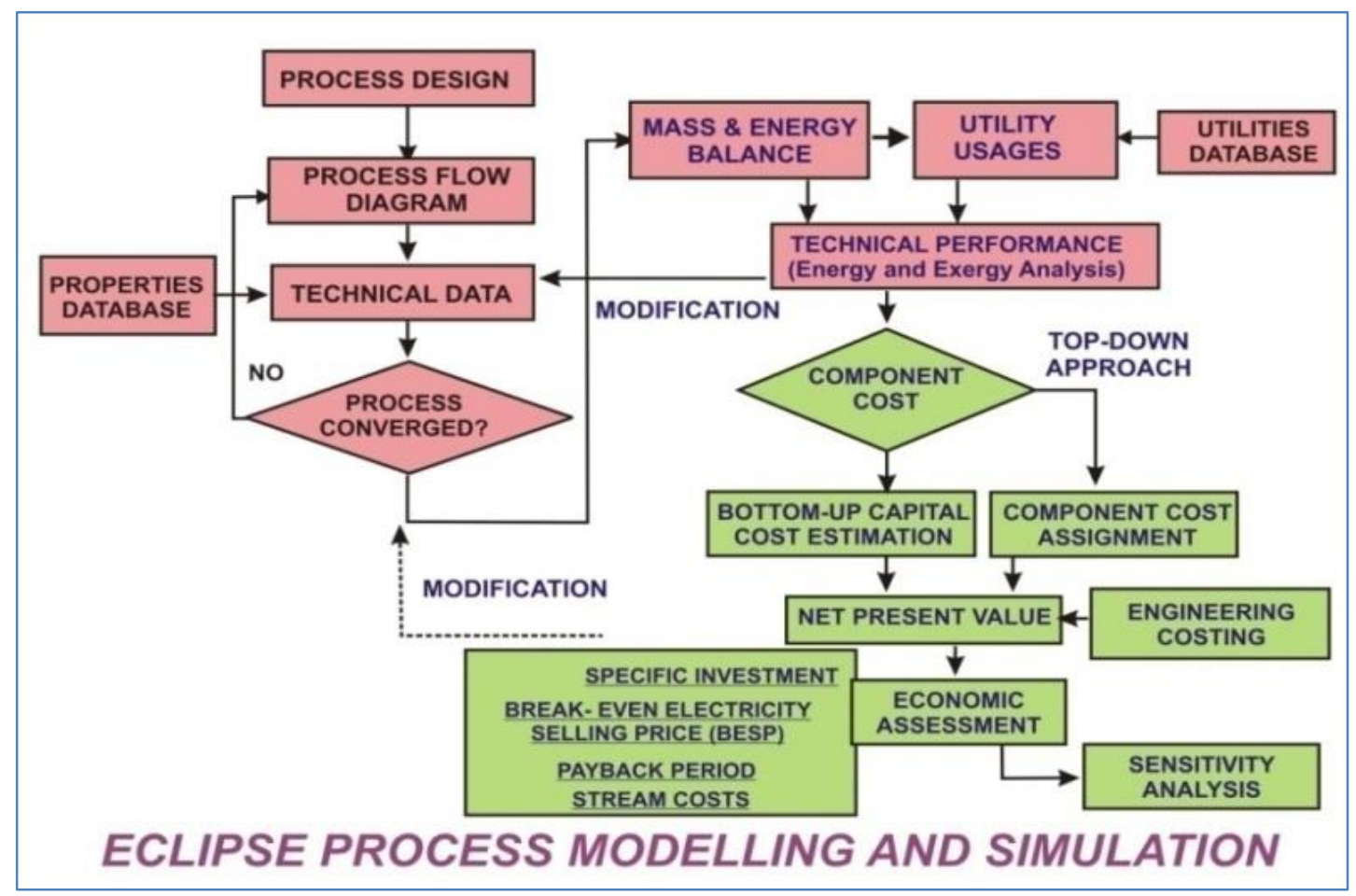

Figure 5 ECLIPSE process modelling and simulation

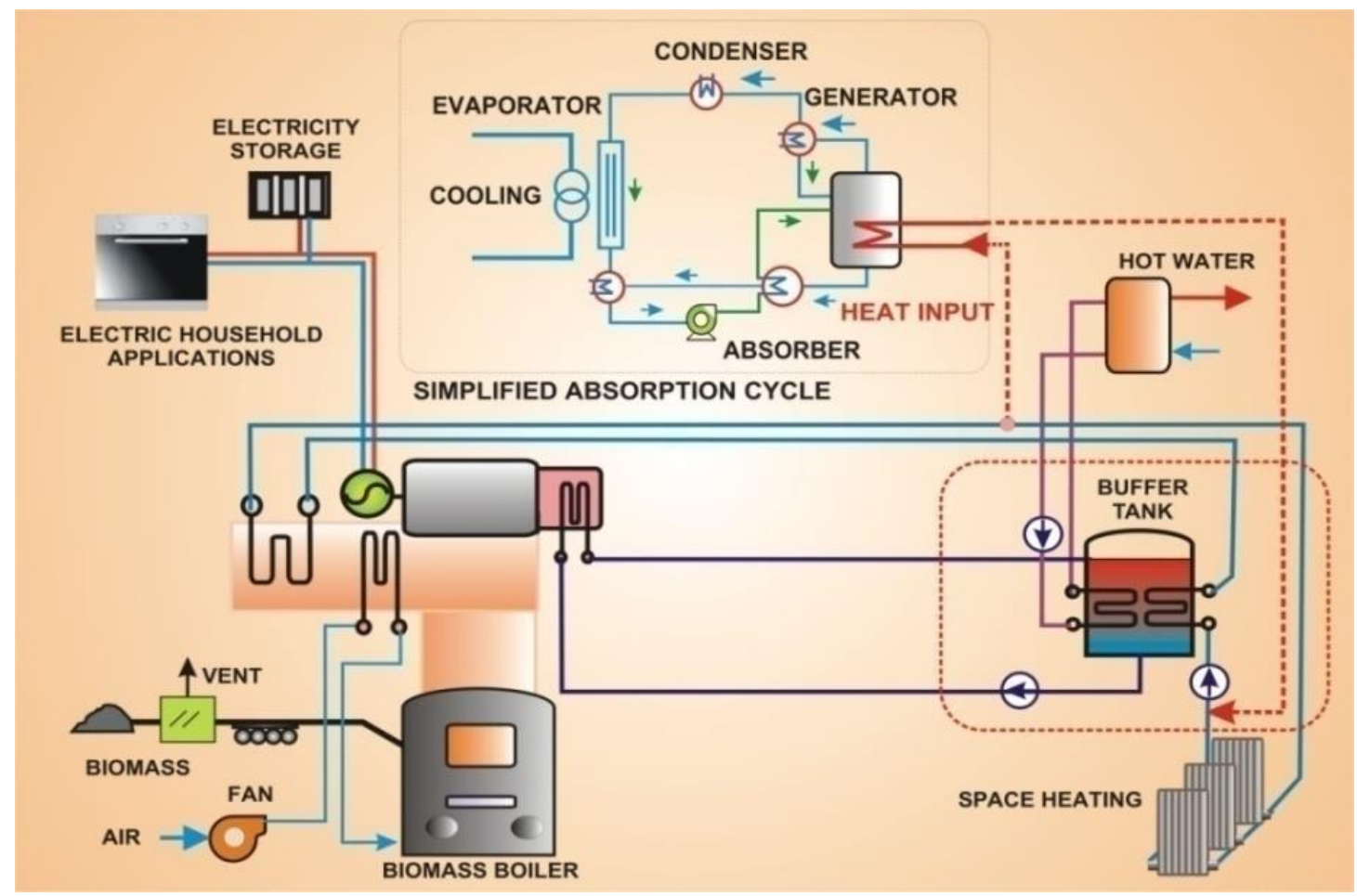

Figure 6 Schematic diagram of the trigeneration system based on a Stirling engine 


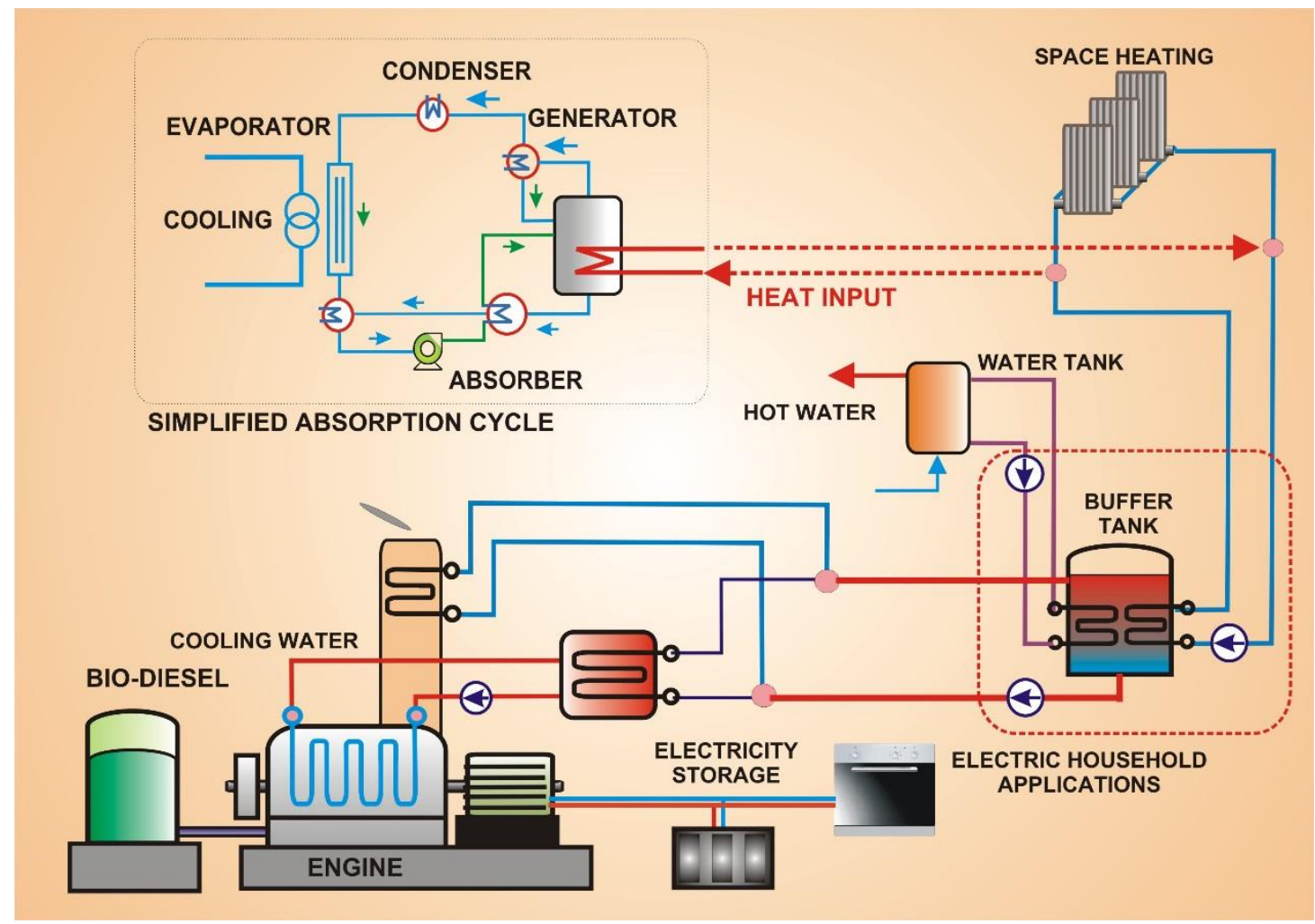

Figure 7 Schematic diagram of the trigeneration system based on an IC engine

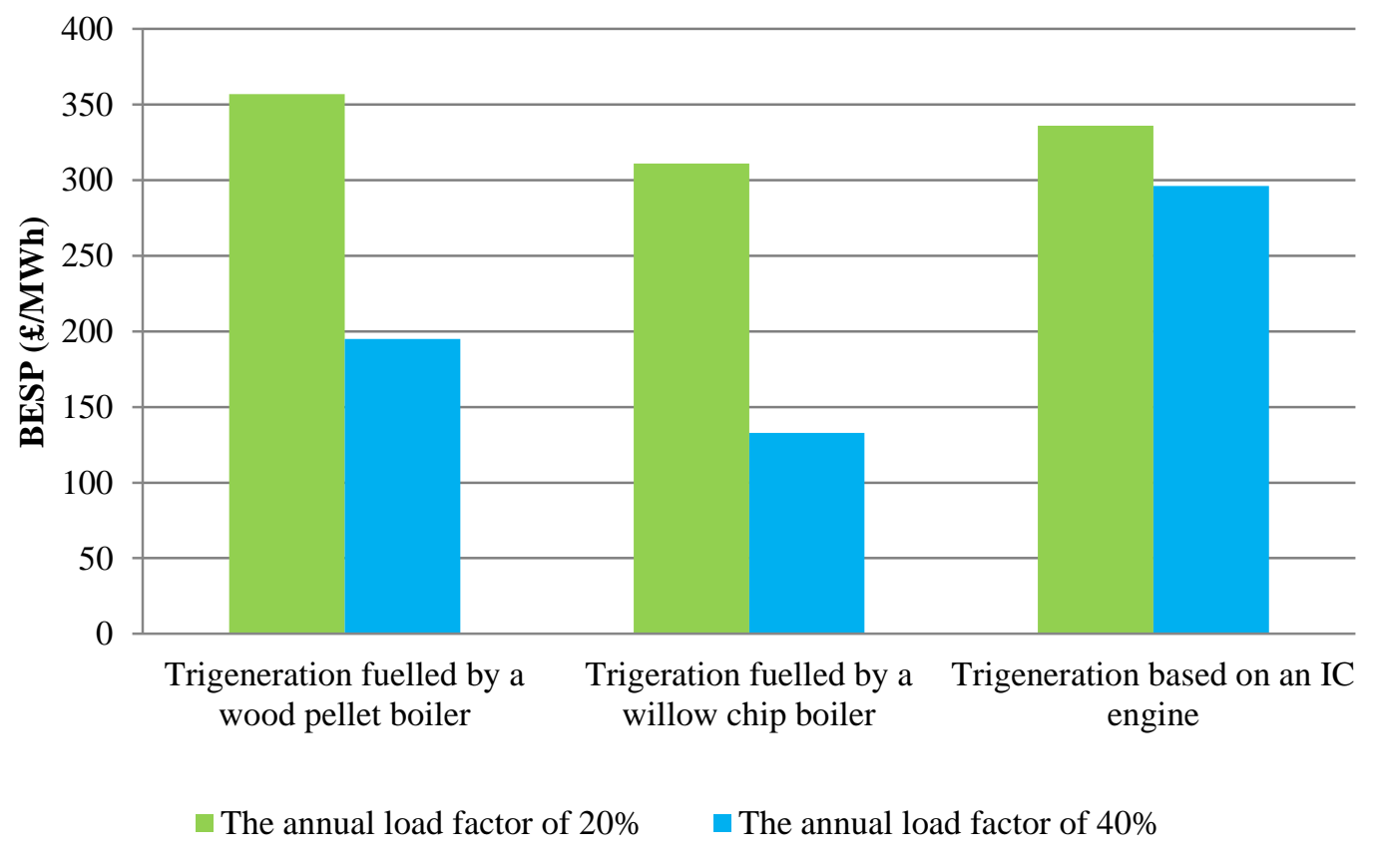

Figure 8 Break-even Electricity Selling Price vs. load factors 


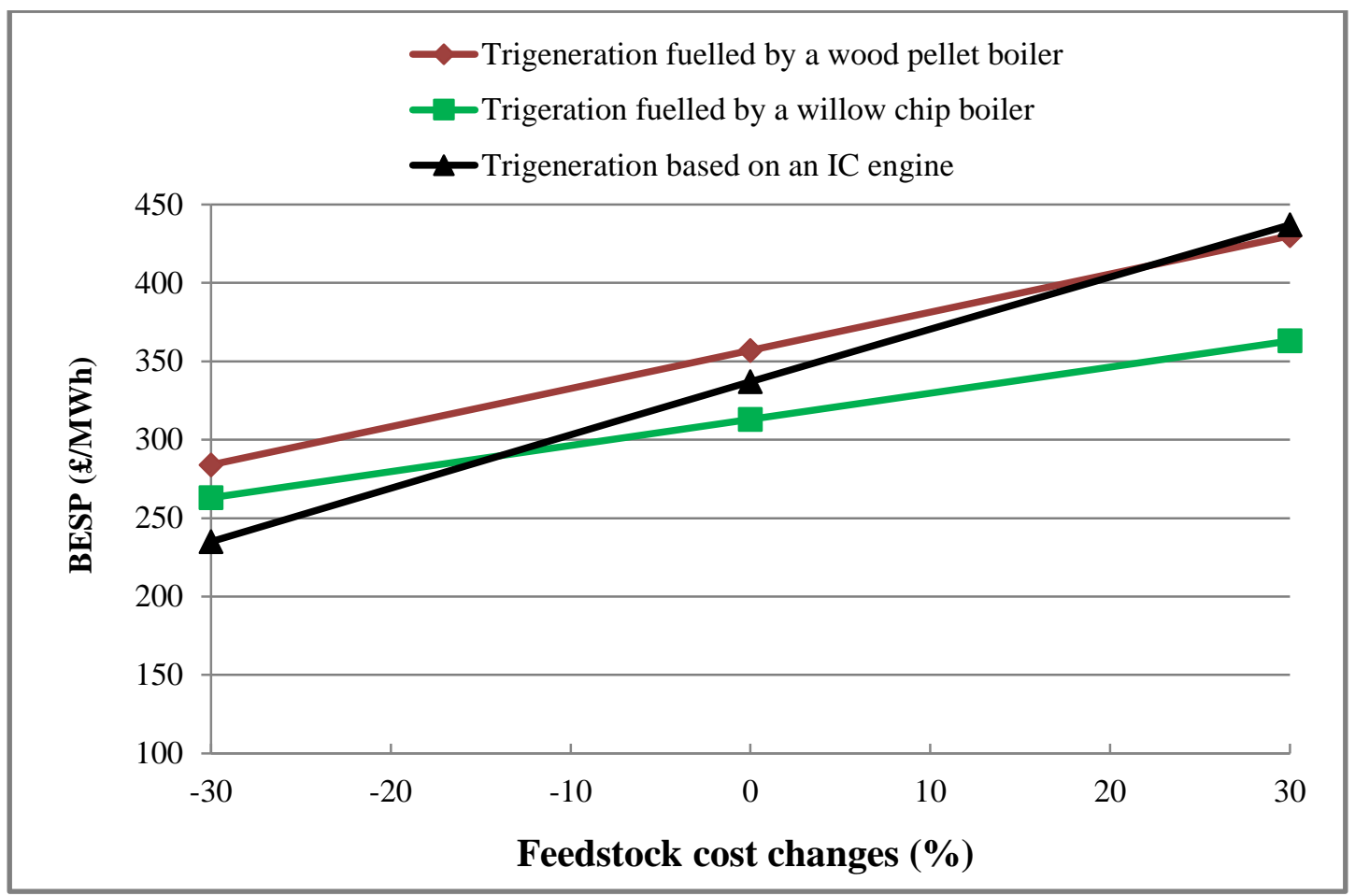

Figure 9 Break-even Electricity Selling Price vs. feedstock costs 
Table 1 Analysis of feedstocks used

\begin{tabular}{|l|c|c|c|}
\hline Fuels & Wood Pellets & Willow Chips ${ }^{[31]}$ & Bio-diesel \\
\hline Water (wt-\% AR) & 10.0 & 30.0 & -- \\
\hline Ash (wt-\% AR) & 0.5 & 6.0 & -- \\
\hline VM \& FC (wt-\% AR) & 89.5 & 64.0 & -- \\
\hline LHV (MJ/kg, AR) & 16.75 & 11.73 & 40.32 \\
\hline Ultimate analysis (wt- \%, DAF) & \multicolumn{3}{|l|}{} \\
\hline Carbon & 51.4 & 51.1 & 85.4 \\
\hline Hydrogen & 6.4 & 6.0 & 11.4 \\
\hline Nitrogen & 0.1 & 0.1 & 0.3 \\
\hline Sulphur & -- & 0.1 & 0.7 \\
\hline Oxygen & 42.1 & 42.7 & 2.2 \\
\hline
\end{tabular}

Table 2 Technical results

\begin{tabular}{|l|c|c|c|}
\hline & Option 1 & Option 2 & Option 3 \\
\hline Feedstock & Wood pellets & Willow chips & Bio-diesel \\
\hline Feedstock input, kg/hr (as received) & 3.60 & 5.36 & 1.53 \\
\hline CV MJ/kg (LHV, as received) & 16.75 & 11.73 & 40.32 \\
\hline Total thermal input, kWth & 16.8 & 17.5 & 17.2 \\
\hline Total thermal output (boiler), kWth & 14.7 & 15.0 & -- \\
\hline Boiler efficiency, \% (LHV) & 87.7 & 85.8 & -- \\
\hline Flue gas temperature, ${ }^{\circ} \mathrm{C}$ & 130 & 130 & 140 \\
\hline Electrical output, $\mathrm{kWe}(\mathrm{Net})$ & 3.2 & 3.2 & 5.2 \\
\hline Overall electricity efficiency, \% & 19.3 & 18.8 & 30.0 \\
\hline Heat output, $\mathrm{kWth}($ maximum) & 10.9 & 11.1 & 7.6 \\
\hline
\end{tabular}




\begin{tabular}{|l|c|c|c|}
\hline $\begin{array}{l}\text { Heat output, kWth (summer } \\
\text { months) }\end{array}$ & 3.6 & 3.7 & 3.7 \\
\hline $\begin{array}{l}\text { Cooling output, kWth (summer } \\
\text { months) }\end{array}$ & 4.4 & 4.5 & 2.2 \\
\hline Overall CHP efficiency, \% & 84.3 & 82.4 & 74.6 \\
\hline Heat/electricity ratio (CHP) & 3.4 & 3.4 & 1.5 \\
\hline Overall trigeneration efficiency, \% & 66.9 & 65.4 & 64.1 \\
\hline $\begin{array}{l}\text { CO } 2 \text { emissions, g/kWh (CHP) } \\
\text { (OO } 2 \text { emissions, g/kWh }\end{array}$ & 515 & 522 & 504 \\
\hline $\begin{array}{l}\text { Reduction in } \mathrm{CO}_{2} \quad \text { emissions, } \\
\text { tonne/year }\end{array}$ & 8.7 & 8.9 & 6.1 \\
\hline
\end{tabular}

Table 3 Economic results

\begin{tabular}{|c|c|c|c|c|}
\hline & $\begin{array}{c}\text { Oil fired } \\
\text { central heating } \\
\text { system }\end{array}$ & Option 1 & Option 2 & Option 3 \\
\hline Feedstock & Heating oil & $\begin{array}{l}\text { Wood } \\
\text { pellets }\end{array}$ & $\begin{array}{c}\text { Willow } \\
\text { chips }\end{array}$ & Bio-diesel \\
\hline Feedstock price, $£ /$ tonne (AR) & 625 & 220 & 100 & 1136 \\
\hline Boiler cost $(£)$ & 1500 & 7000 & 9000 & -- \\
\hline $\begin{array}{l}\text { Heating and cooling systems, } \\
\text { thermal storage tanks, pipe } \\
\text { works, and miscellaneous extra } \\
\text { parts }(£)\end{array}$ & 3500 & 6500 & 6500 & 5500 \\
\hline $\begin{array}{l}\text { Power generation unit and } \\
\text { electric energy storage cost }(\mathfrak{f})\end{array}$ & -- & 8000 & 8000 & 5500 \\
\hline Total process capital costs $(\mathfrak{£})$ & 5000 & 21500 & 23500 & 11000 \\
\hline Specific investment $(£ / \mathrm{kWe})$ & -- & 6656 & 7165 & 2128 \\
\hline Annual fuel supply costs (£) & 1820 & 1280 & 870 & 2830 \\
\hline
\end{tabular}




\begin{tabular}{|l|c|c|c|c|}
\hline $\begin{array}{l}\text { Levelised heat/or cold price, } \\
£ / M W h\end{array}$ & 97 & 97 & 97 & 97 \\
\hline BESP, £/MWh (CHP) & -- & 316 & 270 & 311 \\
\hline BESP, £/MWh (Trigeneration) & -- & 357 & 313 & 336 \\
\hline $\begin{array}{l}\text { BESP, f/MWh (Trigeneration) } \\
\text { if the domestic RHI tariffs } \\
\text { eligible and received }{ }^{[1]}\end{array}$ & -- & 260 & 210 & -- \\
\hline $\begin{array}{l}\text { BESP, £/MWh (Trigeneration) } \\
\text { if both RHI tariff and Feed-in } \\
\text { tariff (FITs }\end{array}$ & -- & 216 & 169 & 310 \\
\hline Annual running time, hours & 1752 & 1752 & 1752 & 1752 \\
\hline
\end{tabular}

${ }^{[1]}$ The Renewable Heat Incentive (RHI) tariff issued by the UK Government will be paid for 7 years at a rate of $12.2 \mathrm{p} / \mathrm{kWh} .{ }^{[2]}$ Feed-in tariff scheme issued the UK Government will be paid for 10 years $(<2 \mathrm{~kW})$ at a rate of $13.2 \mathrm{p} / \mathrm{kWh}$. 


\section{ACKNOWLEDGMENTS}

This research work was carried out as part of the international cooperation project supported by the National International S\&T Cooperative Program of China under grant No. 2014DFA60600 and PORREN: Partnering Opportunities between Europe and China in Renewable Energies and Environmental Industries, CEC-Framework 7 Marie Curie RTN project supported by the European Commission.

\section{REFERENCES}

[1] Y. Tian, C.Y. Zhao, A review of solar collectors and thermal energy storage in solar thermal applications, Applied Energy (2014), Volume104, Pages 538-553

[2] Xing Luo, et al., Overview of current development in electrical energy storage technologies and the application potential in power system operation, Applied Energy (2015), Volume 137, Pages 511-536

[3] Haoran Zhao, et al., Review of energy storage system for wind power integration support, Applied Energy (2015), Volume 137, Pages 545-553

[4] Sanjoy Roy, Performance prediction of active pitch-regulated wind turbine with short duration variations in source wind, Applied Energy (2014), Volume 114, Pages 700-708 [5] Heinimo, J., Junginger, M., Production and trading of biomass for energy - An overview of the global status, biomass and bioenergy (2009), 33, Pages 1310 - 1320

[6] Demirbas, M. F., et al., Biowastes-to-biofuels, Energy Conversion and Management, (2011),

52, Pages $1815-1828$

[7] Y. D. Wang, et al., Tri-generation running with raw Jatropha oil, Fuel Processing Technology (2010), Volume 91, Issue 3, March-2010, Pages 348-353.

[8] A.D. Leslie, et al., The potential for Eucalyptus as a wood fuel in the UK, Applied Energy (2012), Volume 89, Pages 176-182

[9] David Mcllveen-Wright, et al., A technical and economic analysis of three large scale biomass combustion plants in the UK, Applied Energy (2013), Volume 112, Pages 396-404 [10] A Demirbas, Political, economic and environmental impacts of biofuels: A review, Applied Energy (2009), Volume 86, Pages S108-S117

[11] A Rezavidi, et al., Improving Rural Isolated Diesel Powered Electric Utility Services by Hybrid Solar And Wind Energy System, November, 2008, ISES-AP - 3rd International Solar 
Energy Society Conference - Asia Pacific Region (ISES-AP-08) Incorporating the 46th ANZSES Conference.

[12] DECC 2014, Energy Consumption in the UK (2014),

https://www.gov.uk/government/uploads/system/uploads/attachment_data/file/338662/ecuk_cha pter_3_domestic_factsheet.pdf

[13] Charlotte Hussy et al (2014). International comparison of fossil power efficiency and CO2 intensity - Update 2014, http://www.ecofys.com/files/files/ecofys-2014-internationalcomparison-fossil-power-efficiency.pdf

[14] Enrico Saverio Barbieri, et al, Analysis of innovative micro-CHP systems to meet household energy demands, Applied Energy (2012), Volume 97, Pages 723-733

[15] DELTA-Energy \& Environment, 2014, The Benefits of Micro-CHP: A Delta-ee report produced on behalf of COGEN Europe, http://www.cogeneurope.eu/medialibrary/2015/05/19/d6648069/miro$\underline{\text { CHP\%20study_merged.pdf }}$

[16] D. Maraver, et al., Assessment of CCHP systems based on biomass combustion for smallscale applications through a review of the technology and analysis of energy efficiency parameters, Applied Energy, 102 (2013), 1303-13.

[17] Department of Energy and Climate change (2011), Climate: Observations, projections and impacts, http://www.metoffice.gov.uk/media/pdf/t/r/UK.pdf

[18] The University of Ulster, ECLIPSE Process Simulator, Energy Research Centre, Jordanstown, Northern Ireland, 1992.

[19] D McIlveen-Wright, et al., A re-appraisal of wood-fired combustion, Biosource Technology (2001), Volume 76, Pages 183-190.

[20] Yaodong Wang, et al., Reprint of "modelling and simulation of a distributed power generation system with energy storage to meet dynamic household electricity demand", Applied Thermal Engineering, (2013) Volume 53, Pages 312-324.

[21] Biomass Energy Centre, http://www.biomassenergycentre.org.uk

[22]Y. Huang, et al., Biomass Fuelled Tri-generation System in Selected Buildings, Energy Conversion and Management (2011) Volume 52, Issue 6, Pages 2448-2454

[23] Y. Huang, et al, Comparative techno-economic analysis of biomass fuelled combined heat and power for commercial buildings. Applied Energy (2013), Volume 112, Pages 518-525 
[24] M. Salomón et al., Small-scale biomass CHP plants in Sweden and Finland, Renewable and Sustainable Energy Reviews 15 (2011) 4451- 4465.

[25] Renzi M., Brandoni C., Study and application of a regenerative Stirling cogeneration device based on biomass combustion, Applied Thermal Engineering, Volume 67, Issue 1-2, June 2014, Pages 341-351.

[26] C Brandoni, M Renzi, Optimal sizing of hybrid solar micro-CHP systems for the household sector, Applied Thermal Engineering, Volume 75 (2015), Pages 896-907.

[27] S. R. Wood, et al., A techno-economic analysis of small-scale, biomass-fuelled combined heat and power for community housing, Biomass and Bioenergy (2011), Volume 35, Pages 3849-3858.

[28] D. Prando, et al., Biomass gasification systems for residential application: An integrated simulation approach, Applied Thermal Engineering (2014), Volume 71, Pages 152-160. 